\title{
Effects of Propranolol on Osteoclasts Cultured in Vitro
}

\author{
Xiaojuan LI \\ School of Stomatology \\ Lanzhou University, \\ Lanzhou 730000, China \\ e-mail: 414939478@qq.com \\ Jin REN \\ School of Stomatology \\ Lanzhou University, \\ Lanzhou 730000, China, \\ e-mail: 793039925@qq.com
}

\author{
Xiaorui XIE \\ School of Stomatology \\ Lanzhou University, \\ Lanzhou 730000, China, \\ e-mail: 525603782@qq.com
}

\author{
Liling REN* \\ School of Stomatology \\ Lanzhou University, \\ Lanzhou 730000, China, \\ e-mail: renlil@lzu.edu.cn
}

\author{
Jian CAO* \\ Dept of Oral and Maxillofacial Surgery \\ Lanzhou General Hospital,Lanzhou Command \\ Lanzhou 730000, China, \\ e-mail: 249979819@qq.com
}

\begin{abstract}
Objective: To study the effect of propranolol on osteoclasts. Methods: (1)propranolol at the doses of $\mathbf{1 0}^{-}$ ${ }^{2} \mu \mathrm{mol} / \mathrm{ml}, 10^{-3} \mu \mathrm{mol} / \mathrm{ml}, 10^{-4} \mu \mathrm{mol} / \mathrm{ml}$, were added into the osteoclasts for coculture for $72 \mathrm{~h}$, then tartrate-resistant acid phosphatase (TRAP) and toluidine blue staining was used to detect the effects of propranolol on osteoclasts. Results: compared with the control group, $10^{-2} \mu \mathrm{mol} / \mathrm{ml}, 10^{-3} \mu \mathrm{mol} / \mathrm{ml}$, $10^{-4} \mu \mathrm{mol} / \mathrm{ml}$ group of propranolol were able to make the number of osteoclasts and bone resorption area decreased $(\mathrm{P}<$ 0.05) Conclusion different concentrations of propranolol can inhibit osteoclast bone resorption $(P<0.05)$.
\end{abstract}

Keywords- propranolol ,osteoclasts. ,TRAP

\section{INTRODUCTION}

The normal growth and metabolism of bone includs osteogenetic effect of osteoblast and bone resorption effect of osteoclast, both of which interact with each other to achieve a basic balance[1]. The absorption and bone formation depends on osteoblasts and osteoclasts in the basic multicellular unit recruitment, proliferation and differentiation, and it is also effected by the local micro environment and the external mechanical force and systemic neurohumoral factors [2]. The metabolism of bone is affected by the innervation, which has been valued by many researchers [3]. At present, a number of studies have made it clear the sympathetic fibers play an important role in normal bone metabolism and fracture healing [4]. Elefteriou reported in the Journal of Nature that sympathetic nerve exciting can promote bone resorption and decreased bone formation, and the mechanism of which is by stimulating osteoclast activity and promoting osteoclast formation [5]. The increase in sympathetic activity can increase the number and activity of osteoclasts, and increase bone resorption and decreased bone formation, bone loss, and the effect of which is closely related to the activity of beta 2- adrenergic receptor on osteoblasts. The activation of the receptor can increase the expression of RANKL, stimulate osteoclast formation, and then lead to the decrease of bone mass [6]. But there is not yet any report about a beta 2- adrenergic receptor related drugs directly effecting on osteoclasts, so this experiment choose non selective beta adrenergic receptor antagonist propranolol effecting on osteoclasts, to observe the effects of different concentrations of propranolol on osteoclasts, providing a basis for further exploring the mechanism of effects of propranolol on bone metabolism.

\section{MATERIALS AND METHODS}

\section{A. Materials}

1) laboratory animal: 6 newborn rabbits in $24 \mathrm{~h}$, either size or gender is not limited;

2) Major laboratory products and chemical reagents: Propranolol (Sigma), DMEM medium and fetal bovine serum (Hyclone), penicillin streptomycin (Gibco), glutamine (Sigma). Tartrate resistant acid phosphatase (TRAP) staining kit, toluidine blue (Nanjing Jiancheng Biological Engineering Institute); 


\section{B. Experimental Methods}

1) Extraction and culture of rabbit osteoclasts: The newborn rabbits were sacrificed by broken neck, soking in $75 \%$ alcohol for $15 \mathrm{~min}$, taking limbs long bone in aseptic conditions, then putting in cold PBS medium after wipping out soft tissue and epiphyses. Then longitudinally split the backbone in the cold low glucose DMEM medium (containing 15\% fetal bovine serum, penicillin 100IU/ml, chain enzyme $100 \mathrm{mg} / \mathrm{ml}$ ), lightly scraping the inner surface with a sharp knife, and rinsed repeatedly the surface of the medullary cavity with pointed straw until white color ,standing 1min, taking the upper cell suspension seeded on 24 well plates in which preset bone slices or coverslip . Add $0.5 \mathrm{ml}$ cell suspension into each hole ,cultured in carbon dioxide incubator. Replaced the culture solution after $30 \mathrm{~min}$, rinsing off the cells not attached. Later replace the culture fluid after $24 \mathrm{~h}$.

2) Identification of osteoclast

a) Morphological observation: The growth and morphological changes of osteoclasts were observed under the inverted microscope. The visual field was randomly selected and recorded.

b) Tartrate-resistant acid phosphatase (TRAP) staining:Operation according to TRAP staining kit manual.

3) Experimental group:Cells were placed in $37 \mathrm{C}$ and $5 \% \mathrm{CO}_{2}$ for cultured 30min,replaced the culture solution , rinsing off the cells not attached. Then randomly divided into 4 groups $\left(10^{-2} \mu \mathrm{mol} / \mathrm{ml}, 10^{-3} \mu \mathrm{mol} / \mathrm{ml}, 10^{-4} \mu \mathrm{mol} / \mathrm{ml}\right.$ group of propranolol), each group of 6 holes, the experimental group and the control group were changed for conditioned medium after $24 \mathrm{~h}$.

4) Count the positive cell of TRAP: Taking out the coverslip after cultured 72h. According to the TRAP staining kit manual., take photos and record the number of positive cells.

5) Area of bone resorption: Taking out the coverslip after cultured $72 \mathrm{~h}$. Soak in $2.5 \%$ glutaraldehyde solution for 7 10min, and then ultrasonic cleaning by double distilled for $3-5 \min \times 3$ times, dehydration by the series of ethanol , naturally dried, then placed in $1 \%$ toluidine blue for $4-5 \mathrm{~min}$ at room temperature .Microscope, and photography after cleaning,. And the absorption area of the system is calculated by the image analyzer system.

6) Statistical analysis: The data were analyzed with SPSS version 19.0 software package. The differences in the values between the two groups were assessed by the Student's t-test.The statistics results described by means and standard deviations ( $\mathrm{x}^{+-\mathrm{s})}$. The level of statistical significance was set $\mathrm{P}<0.05$.

\section{RESULTS AND ANALYSIS}

\section{A. Cell Morphology Observation}

The number of osteoclast directly extracted is small, the volume is big, and growth is fast. Osteoclast has multiple nuclei, and the number and sizes of the nuclei is different. Cytoplasm is fullness, and Pseudopodia and swelled can be seen between cells. (Fig. 1 )



Figure 1. Morphology of osteoclasts

\section{B. TRAP Staining Results}

After TRAP staining, positive cells can be seen with multiple nuclei, usually 3-5, irregularly in shape, and its nucleolus is obvious , cytoplasm is purple (Fig 2)
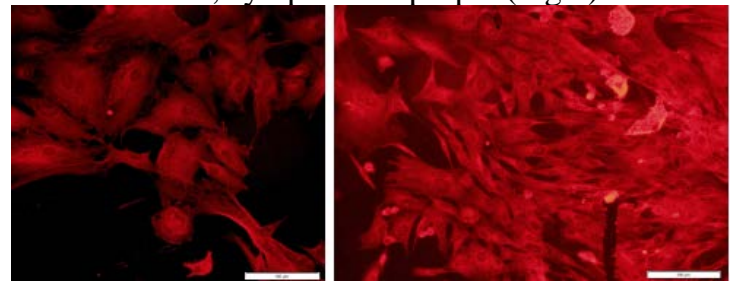

Figure 2. TRAP staining

\section{Effects of Propranolol on Osteoclast Number of TRAP Positive Cells}

The results showed that after $72 \mathrm{~h}$, the number of osteoclasts of $10^{-2} \mu \mathrm{mol} / \mathrm{ml}, 10^{-3} \mu \mathrm{mol} / \mathrm{ml}, 10^{-4} \mu \mathrm{mol} / \mathrm{ml}$ group of propranolol were lower than the control group, the difference was statistically significant $(\mathrm{P}<0.05)$, indicating $10^{-2} \mu \mathrm{mol} / \mathrm{ml}, \quad 10^{-3} \mu \mathrm{mol} / \mathrm{ml}, \quad 10^{-4} \mu \mathrm{mol} / \mathrm{ml}$ group of propranolol can reduce the number of osteoclasts; and the difference between the three groups had statistically significant $(\mathrm{P}<0.05)$, indicating $10-3$ group of propranolol on osteoclast is most obvious. (Table I)

TABLE I. EFFECT OF PROPRANOLOL ON POSITIVE CELls OF TRAP AND AREA OF BONE RESPORTION

\begin{tabular}{|c|c|c|}
\hline \multicolumn{3}{|c|}{ positive cells of TRAP the area of bone resorption } \\
\hline \multicolumn{3}{|c|}{$\left(\mu \mathrm{m}^{2}\right)$} \\
\hline Group & $\bar{X} \pm \mathrm{S}$ & $\bar{X} \pm \mathrm{S}$ \\
\hline Control group & $122.67 \pm 9.87$ & $2315.56 \pm 412.66$ \\
\hline $10^{-2} \mu \mathrm{mol} / \mathrm{ml}$ & $53.00 \pm 5.00$ & $1345.24 \pm 249.02$ \\
\hline $10^{-3} \mu \mathrm{mol} / \mathrm{ml}$ & $22.67 \pm 5.13$ & $344.43 \pm 143.63$ \\
\hline $10^{-4} \mu \mathrm{mol} / \mathrm{ml}$ & $33.33 \pm 1.53$ & $674.83 \pm 105.45$ \\
\hline
\end{tabular}

\section{Analysis of Bone Resorption Lacunae Area}

Osteoclast formed bone resorption lacunae on bone slices, presenting blueviolet after toluidine blue staining, which was 
round, oval or botuliform (Fig. 3). The results showed that bone resorption area of $10^{-2} \mu \mathrm{mol} / \mathrm{ml}, 10^{-3} \mu \mathrm{mol} / \mathrm{ml}, 10^{-}$ ${ }^{4} \mu \mathrm{mol} / \mathrm{ml}$ group of propranolol, were lower than the control group, the difference was statistically significant $(\mathrm{P}<0.05)$; and the difference between the three groups had statistically significant $(\mathrm{P}<0.05)$, indicating $10-3$ group of propranolol on osteoclast is most obvious.

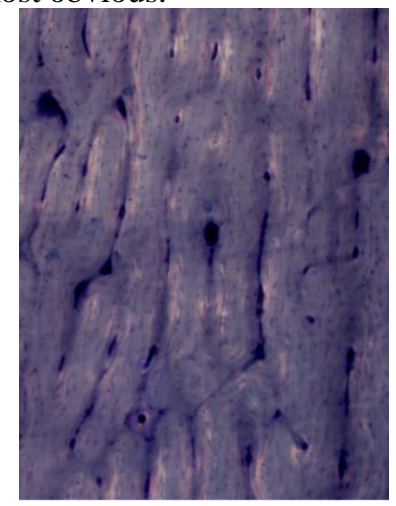

Figure 3. Toluidine blue staining

\section{DISCUSSION}

Osteoclast cells contain abundant acid phosphatase, which was not specific to osteoclast cells, so do osteoblast. [7]. TRAP is one of the six kinds of acid phosphatase isozyme, is a specific marker of osteoclasts, its expression and the secretion are closely related with the function of osteoclasts, which can be used as important identification markers of osteoclasts [8].This experiment found that the cells were red after TRAP staining, containing multiple nuclei, and pseudopodia could be seen between cells, indicateing that the cells was osteoclasts.

Bone resorption lacunae directly reflects the ability of osteoclastic bone resorption, therefore bone resorption lacunae area is an important indicator of bone resorption of osteoclasts[9-10]. The experimental results show that $10^{-}$ ${ }^{2} \mu \mathrm{mol} / \mathrm{ml}, 10^{-3} \mu \mathrm{mol} / \mathrm{ml}, 10^{-4} \mu \mathrm{mol} / \mathrm{ml}$ group of propranolol can reduce the area of bone resorption on bone slices, and this conclusion is consistent with the result after TRAP staining.

\section{CONCLUSIONS}

The effects of different concentrations of propranolol after 72 hours can inhibit osteoclastic bone resorption..

\section{ACKNOWLEDGEMENTS}

The authors gratefully acknowledge the financial supports of Youth Science Project of the National Natural Science Foundation of China (No.81400552),and youth development project of The military medical science and technology (No.13QNP019).

\section{REFERENCE}

[1]. Hou B, Fukai N, Olsen B R. Mechanical force-induced midpalatal suture remodeling in mice. Bone, 2007, 40(6):1483-93.

[2] Kikuta J, Kawamura S, Okiji F, et al. Sphingosine-1-phosphatemediated osteoclast precursor monocyte migration is a critical point of control in antibone-resorptive action of active vitamin D. Proceedings of the National Academy of Sciences of the United States of America, 2013, 110(17):7009-13.

[3] Nagao M, Feinstein T N, Ezura Y, et al. Sympathetic control of bone mass regulated by osteopontin. Proceedings of the National Academy of Sciences, 2011, 108(43):17767-72.

[4] Cherruau M, Bataille C, Hay E, et al. Different sympathetic pathways control the metabolism of distinct bone envelopes. Bone, 2012, 50(5):1162-72.

[5] Elefteriou F, Ahn J D, Takeda S, et al. Leptin regulation of bone resorption by the sympathetic nervous system and CART. Nature, 2005, 434(7032):514-20.

[6] Togari A, Arai M. Pharmacological Topics of Bone Metabolism: The Physiological Function of the Sympathetic Nervous System in Modulating Bone Resorption. Journal of Pharmacological Sciences, 2008, 106(4):542-546.

[7] Suzuki H, Nakamura I, Takahashi N, et al. Calcitonin-induced changes in the cytoskeleton are mediated by a signal pathway associated with protein kinase A in osteoclasts. Endocrinology, 1996, 137(11):4685-90.

[8] Rissanen J P, Suominen M I, Peng Z, et al. Secreted Tartrate-Resistant Acid Phosphatase $5 b$ is a Marker of Osteoclast Number in Human Osteoclast Cultures and the Rat Ovariectomy Model. Calcified Tissue International, 2008, 82(2):108-15.

[9] Kanehisa J, Heersche J N M. Osteoclastic bone resorption: In vitro analysis of the rate of resorption and migration of individual osteoclasts. Bone, 1988, 9(2):73-79.

[10] Liu S, Lei M, Baijing A N, et al. Culture and identification of human osteoclasts in vitro. Medical Journal of the Chinese People's Armed Police Forces, 2011. 